\title{
Relation of zonal plasma drift and wind in the equatorial $F$ region as derived from CHAMP observations
}

\author{
J. Park and H. Lühr \\ GFZ, German Research Centre for Geosciences, Potsdam, Germany \\ Correspondence to: J. Park (park@gfz-potsdam.de)
}

Received: 7 January 2013 - Revised: 15 May 2013 - Accepted: 15 May 2013 - Published: 12 June 2013

\begin{abstract}
In this paper we estimate zonal plasma drift in the equatorial ionospheric $\mathrm{F}$ region without counting on ion drift meters. From June 2001 to June 2004 zonal plasma drift velocity is estimated from electron, neutral, and magnetic field observations of Challenging Mini-satellite Payload (CHAMP) in the 09:00-20:00 LT sector. The estimated velocities are validated against ion drift measurements by the Republic of China Satellite-1/Ionospheric Plasma and Electrodynamics Instrument (ROCSAT-1/IPEI) during the same period. The correlation between the CHAMP (altitude $\sim 400 \mathrm{~km}$ ) estimates and ROCSAT-1 (altitude $\sim 600 \mathrm{~km}$ ) observations is reasonably high $(R \approx 0.8)$. The slope of the linear regression is close to unity. However, the maximum westward drift and the westward-to-eastward reversal occur earlier for CHAMP estimates than for ROCSAT-1 measurements. In the equatorial $\mathrm{F}$ region both zonal wind and plasma drift have the same direction. Both generate vertical currents but with opposite signs. The wind effect (F region wind dynamo) is generally larger in magnitude than the plasma drift effect (Pedersen current generated by vertical E field), thus determining the direction of the $\mathrm{F}$ region vertical current.
\end{abstract}

Keywords. Ionosphere (Equatorial ionosphere)

\section{Introduction}

The ionospheric $\mathrm{F}$ region is an important medium for radio communication. Among a variety of parameters characterizing the $\mathrm{F}$ region, the plasma density is one of the most essential parameters because it determines the reflection height of various radio waves (e.g. Chen et al., 2011), affects the phase delay of wave signals (e.g. Jee et al., 2004; Noja et al., 2013), and disturbs communication links (e.g. Basu et al., 1988, 2001; Nishioka et al., 2011; Manju et al., 2011).
Plasma density in the ionospheric $\mathrm{F}$ region is controlled not only by local ionization/loss processes, but also by plasma transport. Therefore, the climatology of the $\mathrm{F}$ region plasma drift has gained significant attention in ionospheric science. Especially, the vertical drift has direct control over the F layer height, which affects the recombination rate. The majority of previous studies about $\mathrm{F}$ region plasma transport have focused on the vertical drift (e.g. Sastri, 1996; Scherliess and Fejer, 1999; Hartman and Heelis, 2007; Kil et al., 2007; Fejer et al., 2008; Stolle et al., 2008, to name only a few). The horizontal drift (e.g. Coley et al., 1994; Maynard et al., 1995; Fejer et al., 2005; Pacheco et al., 2011), on the other hand, has been given relatively less attention. Zonal drift of $F$ region plasma is generally westward (eastward) during daytime (nighttime) (e.g. Fejer et al., 2005, Fig. 1). As the eastward drift speed at low latitudes is generally stronger than the westward one, the daily average of the zonal drift results in net eastward drift: the so-called super-rotation (e.g. Pacheco et al., 2011). As the latitudes get lower, the super-rotation becomes stronger. The magnitude of zonal drift speed on the dayside (nightside) exhibits weak (strong) positive correlation with the solar $F_{10.7}$ index (e.g. Fejer et al., 2005, Fig. 2). The zonal drift depends on longitude as well as on latitude (e.g. Pacheco et al., 2011).

Although there are a number of papers on the zonal plasma drift, a large number of those studies are restricted to local nighttime because they used equatorial plasma bubbles (EPBs) as a tracer for estimating the zonal plasma drift (e.g. Kil et al., 2002; de Paula et al., 2002; Martinis et al., 2003; England and Immel, 2012). Some of the other extensive studies, which covered the dayside climatology, used groundbased instrumentation at a fixed geographic location (e.g. Fejer et al., 2005). Further studies on the climatology of zonal plasma drift, especially on the dayside, are still warranted. 


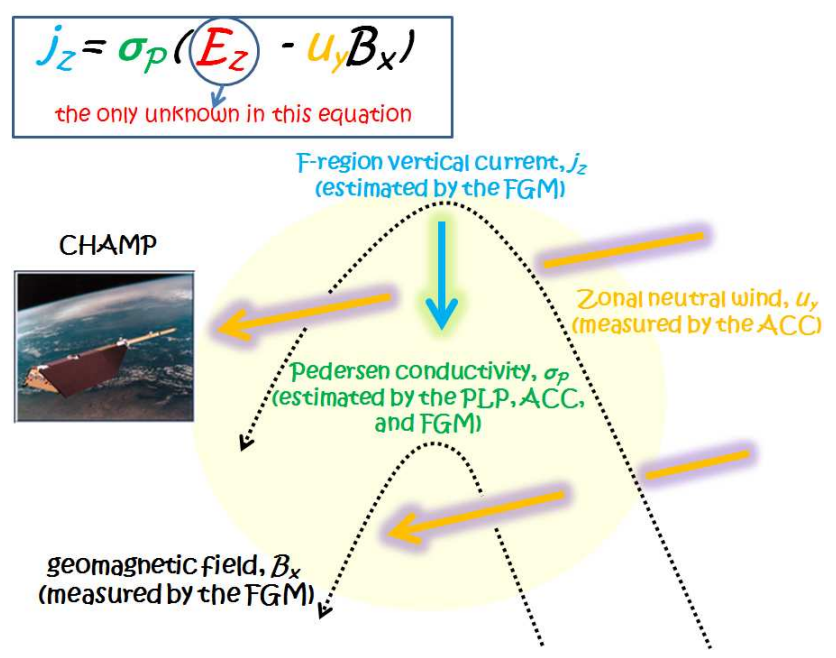

Fig. 1. Schematic diagram of the procedure for estimating zonal plasma drift velocity from CHAMP measurements.

In this paper we estimate zonal plasma drift in the equatorial ionospheric $\mathrm{F}$ region indirectly from the Challenging Mini-Satellite Payload (CHAMP) measurements. We also make direct comparisons between zonal wind and plasma drift in the low-latitude $\mathrm{F}$ region. Furthermore, we assess the influence of these two components on the vertical current flowing in the equatorial F region. In Sect. 2 the instruments and the derivation methods are described. The estimated velocities are presented and validated in Sect. 3. The climatology of the zonal drift is discussed in Sect. 4, and we draw conclusions in Sect. 5.

\section{Instrumentation and method}

The CHAMP satellite was launched on 15 July 2000 into a circular polar orbit. The orbit altitude was about $450 \mathrm{~km}$ right after launch, and decayed slowly until the atmospheric re-entry on 19 September 2010. The orbit inclination angle was $87.2^{\circ}$, so the local time (LT) changed by $12 \mathrm{~h}$ over 131 days. The main purpose of CHAMP was precise measurement of geomagnetic field, which was performed by the Overhauser Magnetometer (OVM) and the Flux-Gate Magnetometer (FGM). The pre-processed data rate is $1 \mathrm{~Hz}$. The Space Triaxial Accelerometer for Research (STAR or ACC) is the on-board accelerometer, from which we can get information on the neutral mass density and cross-track wind velocity (approximately in the zonal direction in geographic coordinates) every $10 \mathrm{~s}$. The Planar Langmuir Probe (PLP) measures electron density and temperature every $15 \mathrm{~s}$. CHAMP also carried a Digital Ion Drift Meter (DIDM), which could have directly measured the three-dimensional plasma drift velocity. Unfortunately, the DIDM was degraded severely during launch. We can only get relative ion density variation from the DIDM. Below we describe how the zonal drift speed can be retrieved from the combined observations of the FGM, ACC, and PLP.

The geomagnetic field vectors observed by the FGM reflect a variety of source current systems - e.g. in Earth's core, crust, ionosphere, and magnetosphere. In this study we are only interested in the ionospheric currents. Therefore, the contributions from Earth's core, crust, and magnetosphere (hereafter called "mean field" or "mean geomagnetic field") are modelled and subtracted from the FGM observations. We use the Pomme6 model (http://www.geomag.us/ models/pomme6.html) for this study. The result of the subtraction (hereafter, "residual field") is considered as reflecting ionospheric currents. The residual field is transformed into the mean-field-aligned (MFA) coordinates. The $\mathrm{x}$-axis is parallel to the mean field (hereafter, "parallel component"), $y$-axis perpendicular to the magnetic meridian pointing eastward (hereafter, "zonal component"), and z-axis completes the right-handed triad and is pointing towards lower L shells (hereafter, "meridional component"). In this study we only use the zonal (y) component of the residual field.

The vertical current density flowing in the equatorial ionospheric $\mathrm{F}$ region, $j_{\mathrm{z}}$, can be described by the following equation (e.g. Park and Lühr, 2012):

$j_{\mathrm{z}}=\sigma_{\mathrm{P}}\left(E_{\mathrm{z}}-u_{\mathrm{y}} B_{\mathrm{x}}\right)$,

where $\sigma_{\mathrm{P}}$ is the local Pedersen conductivity, $E_{\mathrm{z}}$ the vertical electric field, $u_{\mathrm{y}}$ the zonal wind, and $B_{\mathrm{x}}$ the mean geomagnetic field at the equator. The first term on the right-hand side reflects the current originating from the polarization E field. The second term is the $\mathrm{F}$ region dynamo current driven by $\mathrm{F}$ region zonal wind (see e.g. Lühr and Maus, 2006). Most of the terms in Eq. (1) can be deduced from the CHAMP observations (refer to the schematic diagram in Fig. 1). The vertical current density $\left(j_{\mathrm{z}}\right)$ on the left-hand side can be estimated when the CHAMP/FGM observations of zonal magnetic deflection are interpreted in terms of the Ampere's law.

$j_{\mathrm{z}} \approx \frac{1}{\mu_{0}} \frac{\partial b_{\mathrm{y}}}{\partial x}$,

where $\mu_{0}$ is the permeability of free space, and $\partial b_{\mathrm{y}}$ is the spatial change of the zonal magnetic field between positions $x$ and $x+\partial x$. The ambient magnetic field, $B_{\mathrm{x}}$ (in the second term on the right-hand side of Eq. 1), is also measured by CHAMP/FGM. The CHAMP/ACC observes the cross-track (practically zonal in geographic coordinates) wind, which we approximate as $u_{\mathrm{y}}$ in Eq. (1). The Pedersen conductivity, $\sigma_{\mathrm{P}}$, can be estimated using plasma and neutral density values (Schunk and Nagy, 2009, Sect. 4.8, Table 4.5), which are directly measured by CHAMP/PLP and deduced from CHAMP/ACC data, respectively. Hence, the only unknown parameter in Eq. (1) is the vertical E field, $E_{\mathrm{Z}}$ (or, equivalently, zonal plasma drift velocity, $E_{\mathrm{z}} / B_{\mathrm{x}}$ ). Solving for this unknown, the zonal plasma drift velocity at the equator is expressed by the following equation (e.g. Park and Lühr, 2012): 


\section{Results}

$$
\begin{aligned}
v_{\mathrm{y}}=\frac{E_{\mathrm{z}}}{B_{\mathrm{x}}} & =\frac{j_{\mathrm{z}}}{\sigma_{\mathrm{P}} B_{\mathrm{x}}}+u_{\mathrm{y}}=\frac{j_{\mathrm{z}} B_{\mathrm{x}}^{2}}{v_{\mathrm{in}} n_{\mathrm{e}} m_{\mathrm{i}} B_{\mathrm{x}}} \\
& +u_{\mathrm{y}} \\
& =\frac{j_{\mathrm{z}} B_{\mathrm{x}}^{2}}{3.67 \times 10^{-17} n_{\mathrm{n}} \sqrt{T_{\mathrm{r}}}\left(1-0.064 \log _{10} T_{\mathrm{r}}\right)^{2} n_{\mathrm{e}} m_{\mathrm{i}} B_{\mathrm{x}}} \\
& +u_{\mathrm{y}} \\
& \approx \frac{j_{\mathrm{z}} B_{\mathrm{x}}^{2}}{3.67 \times 10^{-17} \frac{\rho}{m_{\mathrm{n}}} \sqrt{T_{\mathrm{r}}}\left(1-0.064 \log _{10} T_{\mathrm{r}}\right)^{2} n_{\mathrm{e}} m_{\mathrm{i}} B_{\mathrm{x}}} \\
& +u_{\mathrm{y}},
\end{aligned}
$$

where $\nu_{\text {in }}$ is ion-neutral collision frequency (in s ${ }^{-1}$ ), $n_{\mathrm{e}}$ electron density (in $\mathrm{m}^{-3}$ ), $m_{\mathrm{i}}$ mean mass of ions (in $\mathrm{kg}$ ), $n_{\mathrm{n}}$ neutral number density (in $\mathrm{m}^{-3}$ ), $T_{\mathrm{r}}$ the arithmetic mean of neutral and ion temperatures (in K), $\rho$ neutral mass density (in $\mathrm{kg} \mathrm{m}^{-3}$ ), and $m_{\mathrm{n}}$ the mean mass of neutral particles (in $\mathrm{kg}$ ). We have deduced the temperature $T_{\mathrm{r}}$ from the International Reference Ionosphere (IRI)-2012 (http: //omniweb.gsfc.nasa.gov/vitmo/). For environmental conditions similar to those prevailing during the considered period $\left(F_{10.7} \approx 155\right.$, height $\left.=400 \mathrm{~km}, \mathrm{LT}=15 \mathrm{~h}\right)$ we obtain $T_{\mathrm{r}} \approx$ $1200 \mathrm{~K}$. Also, we have assumed that $m_{\mathrm{i}}$ is the oxygen mass based on the IRI-2012, and $m_{\mathrm{n}} \approx 1.2 \times m_{\mathrm{i}}$ based on the Mass-Spectrometer-Incoherent-Scatter (MSIS) model (http: //omniweb.gsfc.nasa.gov/vitmo/).

The Republic of China Satellite-1 (ROCSAT-1, also known as FORMOSAT-1) is Taiwan's first scientific satellite, launched in 1999. Its orbital altitude is $600 \mathrm{~km}$, and the inclination angle is about $35^{\circ}$ (e.g. Su et al., 2001). Note that the orbit altitude is higher than that of CHAMP. The Ionospheric Plasma and Electrodynamics Instrument (IPEI) measures cold plasma parameters such as ion density/temperature/composition and 3-dimensional plasma drift velocity. The IPEI operated during the solar maximum period from March 1999 to June 2004. In this study zonal plasma drift (perpendicular to the geomagnetic field) with $1 \mathrm{~s}$ resolution is used (data available at http://cdaweb.gsfc.nasa. gov/). In the ROCSAT-1 data set, zonal drift speed exceeding $500 \mathrm{~m} \mathrm{~s}^{-1}$ is deemed unreasonable and neglected in the data binning. As the processed CHAMP/ACC data are available only from June 2001, we use the period from June 2001 to June 2004 in this study. Further, we restrict ourselves to the sector from 08:30 to 20:30 LT. For the other LT bins the reliability of the method described above is expected to be low because (1) the F region vertical current is weak (e.g. Park et al., 2010, Fig. 3), and (2) zonal wind exhibits large variability in comparison to the mean value (e.g. Liu et al., 2006, Fig. 3).
In this study we are focusing on the statistical properties of the low-latitude $\mathrm{F}$ region dynamics. For that reason the CHAMP data of June 2001-June 2004 are binned in cells of $3^{\circ}$ in magnetic latitude (MLAT), $20^{\circ}$ in geographic longitude (GLON), and $1 \mathrm{~h}$ in LT. Thanks to the large number of readings, we could further subdivide the entries into the three seasons: combined equinoxes, June solstice, and December solstice. For each season, measurements for $\sim 131$ days, during which CHAMP can sample all LT sectors, have been used. Note that each solstice overlaps with equinox for a few days at the borders. As we are interested in the climatological features of the $\mathrm{F}$ region dynamics, geomagnetically active days with daily $\mathrm{Kp}>4$ are skipped. Bin averages for all the quantities needed in Eq. (3) are calculated. These are the magnetic field vectors, neutral density and zonal wind, and the electron density. To calculate the $\frac{1}{\mu_{0}} \frac{\partial b_{\mathrm{y}}}{\partial x}$ term in Eq. (2), we first apply linear detrend and the discrete Fourier transform (DFT) to each MLAT profile of $b_{\mathrm{y}}$, and extract the latitudinally antisymmetric component (e.g. Park et al., 2010). Then, the latitudinal gradient of that component around the geomagnetic equator is calculated by linear regression within $\pm 6^{\circ}$ MLAT, which is $\frac{\partial b_{\mathrm{y}}}{\partial x}$.

We have obtained the bin averages of the ionospherethermosphere parameters around the peak of solar cycle 23 (June 2001-June 2004) with an average solar flux level of $F_{10.7} \approx 155$. One of the prime drivers of the low-latitude ionospheric dynamics is the zonal wind. Figure 2 shows the observed mean zonal wind above the magnetic equator at about $400 \mathrm{~km}$ altitude. Colour-coded velocities are plotted into GLON versus LT frames separately for each of the three seasons. The standard deviation and standard error of the mean are calculated in each bin (GLON $\times \mathrm{LT} \times$ season). Between 09:00 LT and 20:00 LT the standard deviation (standard error of the mean) in each bin is $40-50 \mathrm{~m} \mathrm{~s}^{-1}$ (4$5 \mathrm{~m} \mathrm{~s}^{-1}$ ) on average. These values are smaller than the natural diurnal variation range of zonal wind velocity (i.e. within about $\pm 150 \mathrm{~m} \mathrm{~s}^{-1}$ ). This means that Fig. 2 closely represents the diurnal behaviour of zonal wind. CHAMP observations reveal the well-known characteristics of the lowlatitude zonal wind: westward (negative) winds prevail during daytime and eastward in the evening (e.g. Coley et al., 1994). The direction switches around 16:00 LT. On a diurnal cycle the westward wind maximizes before noon. The daytime westward wind speed is higher than $100 \mathrm{~m} \mathrm{~s}^{-1}$ around the diurnal peak.

The zonal plasma drift $\left(v_{\mathrm{y}}\right)$ as estimated from Eq. (3) is presented in Fig. 3 in the same format and colour scale as in Fig. 2. We see LT dependences very similar to those of Fig. 2. Both plasma and wind move in the same direction with the switch-over around 16:00 LT, but the wind is a little faster in both (westward and eastward) directions. Westward plasma drifts peak before noon just as the westward neutral winds 

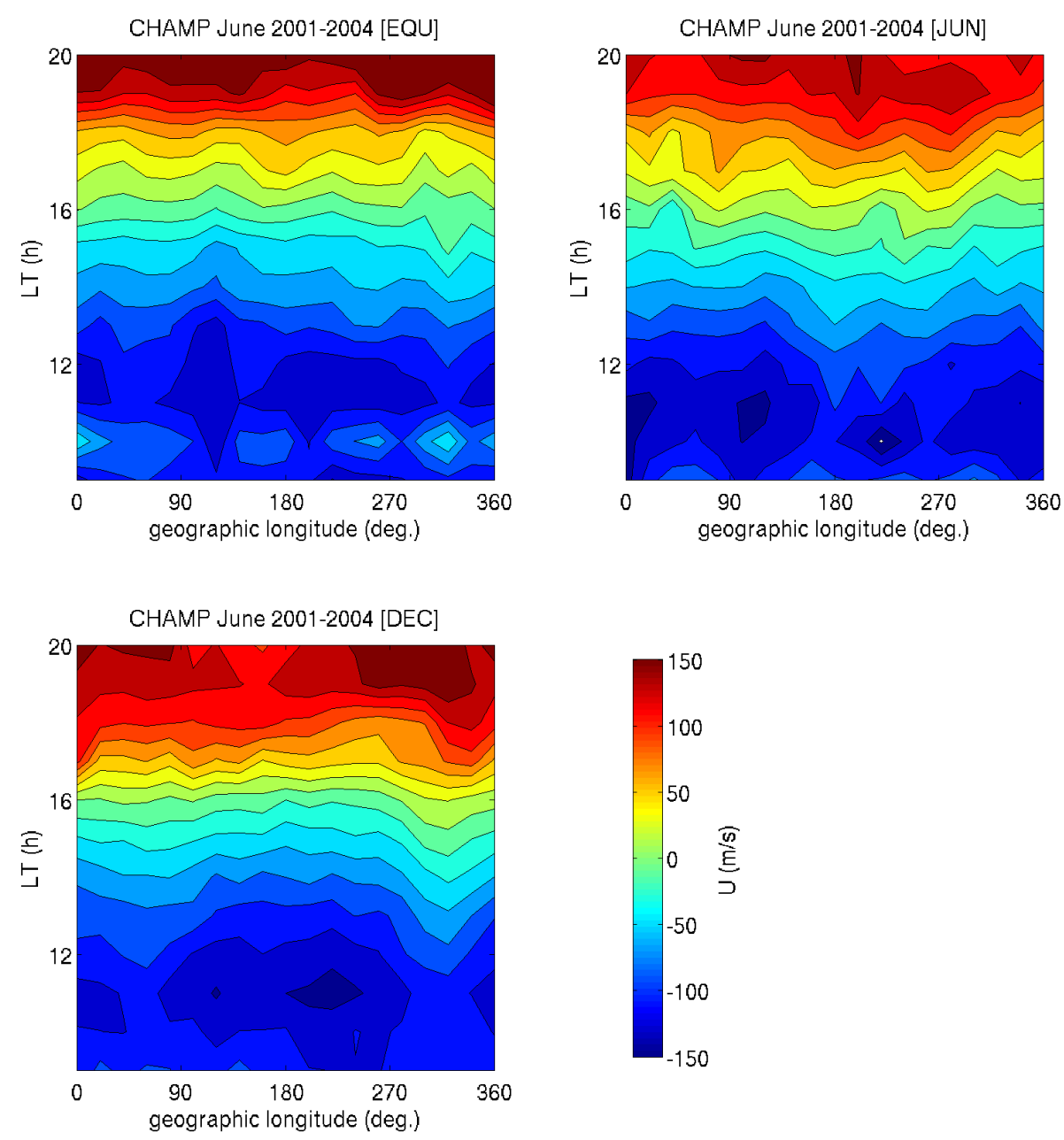

Fig. 2. Average cross-track (nearly zonal) wind velocity estimated from the CHAMP observations. Each panel corresponds to a season.

shown in Fig. 2. Equation (3) contains an empirical relation of the Pedersen conductivity, whose accuracy is not known to us, and we have introduced several assumptions to solve Eq. (3). Hence, it is not straightforward to determine error bars for $v_{\mathrm{y}}$ in Fig. 3. Instead we describe the sensitivity of $v_{\mathrm{y}}$ in Fig. 3 to some independent variables. First, the spread of zonal wind speed, as shown in the preceding paragraph, enters directly the spread of $v_{\mathrm{y}}$ (see Eq. 3). Second, the $v_{\mathrm{y}}$ in Fig. 3 is affected by the assumed value of $T_{\mathrm{r}}$. We have used $T_{\mathrm{r}}=1000 \mathrm{~K}$ and $1400 \mathrm{~K}$. Both of the values lead to deviations, with respect to the case of $T_{\mathrm{r}}=1200 \mathrm{~K}$, at most by $18 \mathrm{~m} \mathrm{~s}^{-1}$. As the variation range of $v_{\mathrm{y}}$ is about $\pm 100 \mathrm{~m} \mathrm{~s}^{-1}$, these uncertainties cannot compromise the results presented in Fig. 3 severely.

From Eq. (1) we know that both the zonal wind and the vertical component of the polarization electric field (or, equivalently, the zonal plasma drift) contribute to the F region vertical current. The net current density can be estimated from CHAMP magnetic field measurements using Eq. (2) (see also Lühr and Maus, 2006). Combining CHAMP observations (FGM, PLP, and ACC) we can also quantify the relative contributions of the two constituents to the net F region vertical current. Figure 4 shows a comparison of the current contributions averaged over all GLON sectors and seasons. As the right-hand side of Eq. (2) is obtained by the Fourier decomposition and linear regression, it is not straightforward to add error bars to $J_{\text {net }}$ in Fig. 4. Instead we estimate the variability of $J_{\text {net }}$ as follows. The standard error of the mean $b_{\mathrm{y}}$ within $\pm 6^{\circ}$ MLAT is $0.5-0.6 \mathrm{nT}$ on average, and the linear regression is conducted within the MLAT range. Therefore, the error of $\frac{\partial b_{\mathrm{y}}}{\partial x}$ is approximately $(0.6 \mathrm{nT}) /\left(6^{\circ}\right)$, which corresponds to an error of $0.7 \mathrm{nAm}^{-2}$ for $J_{\text {net }}$. As described above, the standard error of the mean zonal wind is generally $4-5 \mathrm{~m} \mathrm{~s}^{-1}$. This value corresponds to error of about $2 \mathrm{nAm}^{-2}$ for $J_{\text {dynamo. In general, these er- }}$ rors are small in comparison to the variation ranges of $J_{\text {net }}$, $J_{\text {Pedersen, }}$, and $J_{\text {dynamo, }}$, implying that Fig. 4 shows representative behaviours of the currents. It is quite obvious that the polarization electric field drives a current in the direction opposite to the $\mathrm{F}$ region dynamo wind. The amplitude of the 

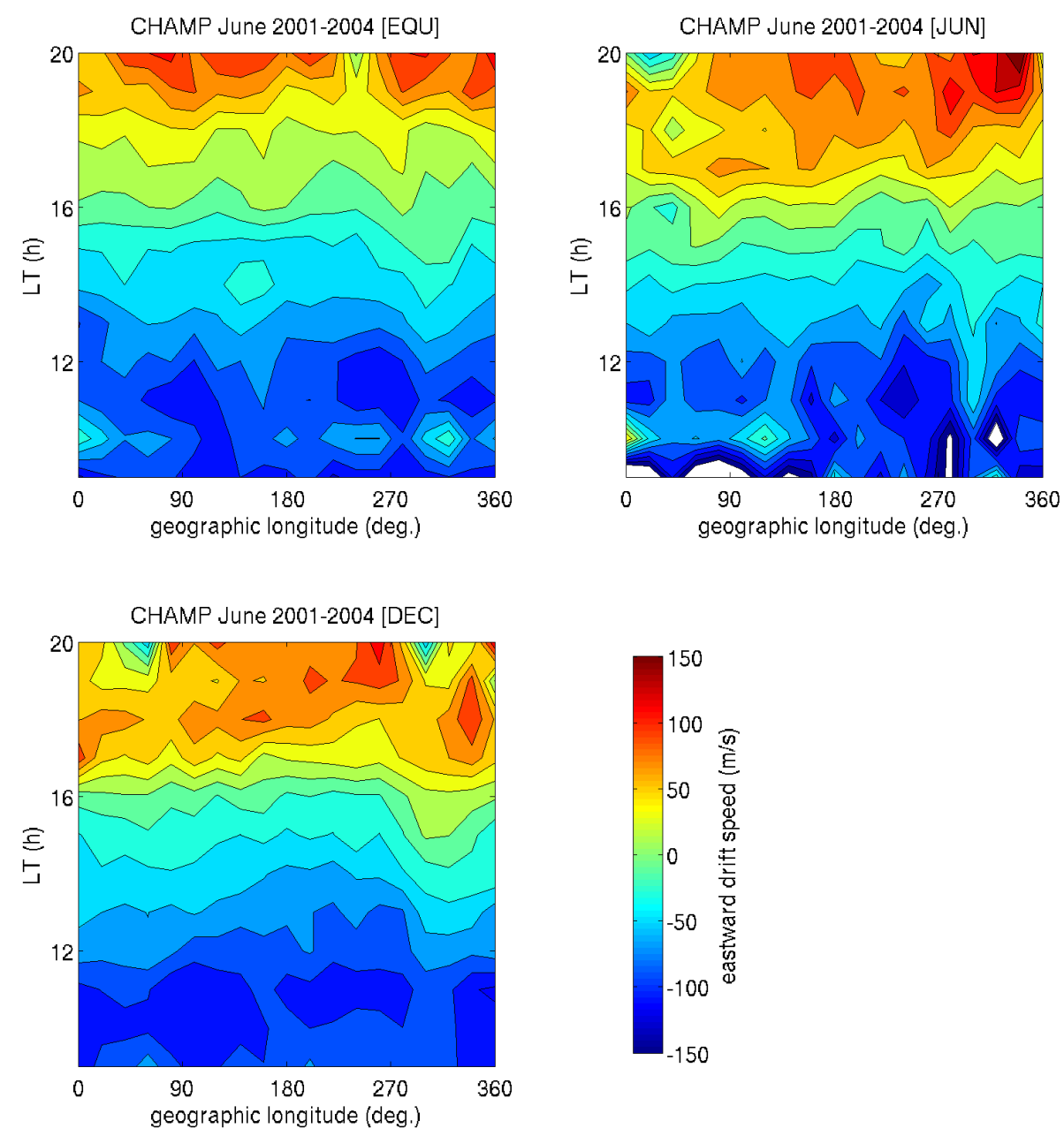

Fig. 3. Zonal plasma drift velocity estimated from CHAMP observations, in the same format as that of Fig. 2.

observed net current is therefore only a small fraction of the magnitude of the currents driven by the $\mathrm{F}$ region wind dynamo. Still, the dominance of the $\mathrm{F}$ region wind dynamo controls the polarity of the net $\mathrm{F}$ region vertical currents. It is interesting to see that the independently measured wind velocity and current density switch their signs at nearby points around 16:00 LT.

To validate the zonal plasma drift $\left(v_{\mathrm{y}}\right)$ in Fig. 3 we considered plasma drift data from ROCSAT-1. These measurements have been binned in the same way as the CHAMP readings. The ROCSAT-1 zonal plasma drifts, which were averaged within $\pm 1.5^{\circ}$ MLAT, are displayed in Fig. 5, in just the same format and colour scale as in Fig. 3. The standard deviation and standard error of the mean are calculated in each bin $(\mathrm{GLON} \times \mathrm{LT} \times$ season). Between 09:00 LT and 20:00 LT the standard deviation (standard error of the mean) in each bin is $40-50 \mathrm{~m} \mathrm{~s}^{-1}$ (about $1 \mathrm{~m} \mathrm{~s}^{-1}$ ) on average. These values are smaller than the variation range of $v_{\mathrm{y}}$ (i.e. within about $\pm 100 \mathrm{~m} \mathrm{~s}^{-1}$ ), which suggests that Fig. 5 closely describes the representative behaviour of $v_{\mathrm{y}}$. As a cross check we compare our Fig. 5 with Su et al. (2009), who also used the ROCSAT-1 zonal drift data during a similar period of time. Notable features in Figs. 3-4 of Su et al. (2009) can be summarized as follows. In December-January daytime $v_{\mathrm{y}}$ generally exhibits weaker LT dependence than in June-July. The magnitude of daytime $v_{\mathrm{y}}$ in December-January is generally smaller than that in June-July. Westward-to-eastward reversal time is generally later (near 18:00 LT) in June-July than in DecemberJanuary (near 16:00 LT). Westward-to-eastward reversal time in June-July (December-January) is latest (earliest) around $330^{\circ}$ E GLON. All these features are in good agreement with our Fig. 5.

In the following we compare Figs. 3 and 5 in detail. In both figures, $v_{\mathrm{y}}$ reversal time during December solstice is earlier around $330^{\circ} \mathrm{E}$ GLON than in the other GLON sectors. For June solstice, drift reversal is latest around $330^{\circ} \mathrm{E}$ GLON in Fig. 5 (ROCSAT-1), while this tendency is barely observable in Fig. 3 (CHAMP). Also, the diurnal variation range of $v_{\mathrm{y}}$ is slightly smaller for ROCSAT-1 (Fig. 5) than for CHAMP (Fig. 3). The sign change of $v_{\mathrm{y}}$ occurs later for 


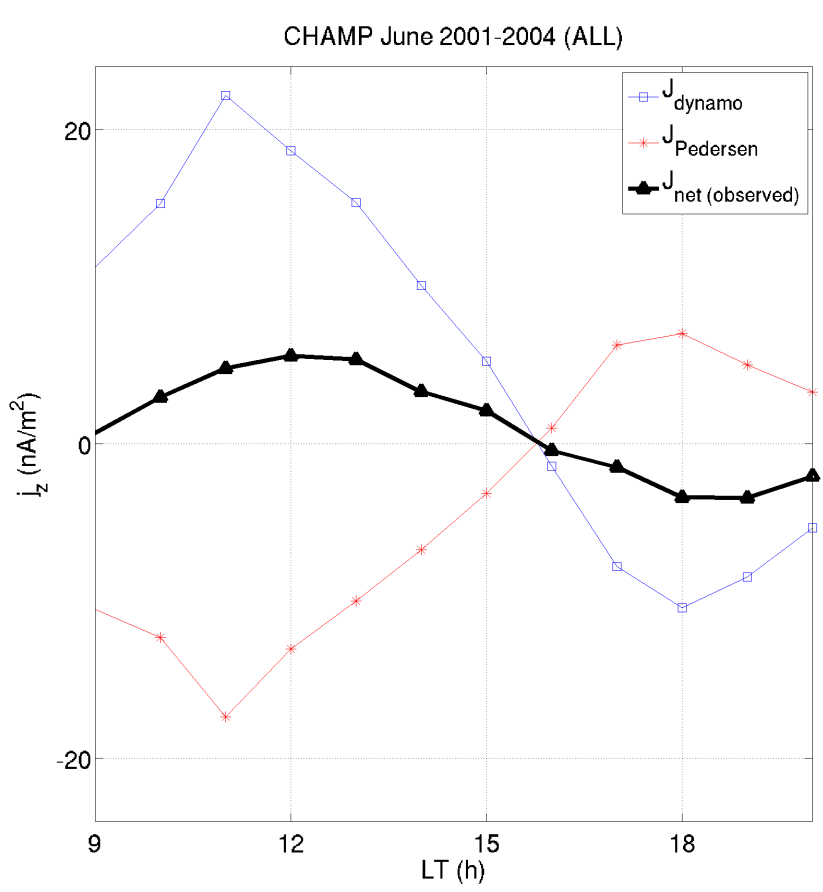

Fig. 4. Comparison of the contributors to the net $F$ region vertical current: the $\mathrm{F}$ region dynamo current driven by $\mathrm{F}$ region zonal wind and the $\mathrm{F}$ region Pedersen current driven by the polarization electric field.

ROCSAT-1 than for CHAMP around June solstice (by about $2 \mathrm{~h}$ in LT). Moreover, the peak westward drift as observed by ROCSAT-1 occurs in the afternoon sector, especially during equinoxes and June solstice. Note that the westward drift as estimated from CHAMP data (Fig. 3) generally maximizes before noon.

Figure 6 presents the correlation between $v_{\mathrm{y}}$ from ROCSAT-1 (x-axis) and CHAMP (y-axis) separately for each season in the form of scatter plots. The bottomright panel contains all the data points combined. Each point in Fig. 6 corresponds to one bin in Figs. 3 and $5($ GLON $\times$ LT $\times$ season $)$. The correlation coefficients are quite high. For December and equinox seasons they reach almost 0.9, which confirms the close agreement between the two independent data sets. Also the slopes of the robust linear regression lines are close to unity (see the equations in each panel). Of the three seasons, the correlation coefficient is lowest during June solstice, but still as high as 0.75 . Some systematic differences between CHAMP and ROCSAT-1 are worth discussing. For highly negative (westward) velocities, ROCSAT-1 values go into saturation with respect to those estimated by CHAMP. Conversely, ROCSAT-1 observes slightly larger positive (eastward) velocities than those estimated by CHAMP except for June solstice. Good agreements are achieved in the range $v_{\mathrm{y}}=$ $\pm 50 \mathrm{~m} \mathrm{~s}^{-1}$. During June solstice months a bias between the ROCSAT-1 data and CHAMP estimates appears to be about
$-50 \mathrm{~m} \mathrm{~s}^{-1}$, which leads to the large intercept $\left(37.8 \mathrm{~m} \mathrm{~s}^{-1}\right)$ of the regression equation. In summary, the zonal plasma drifts from ROCSAT-1 and CHAMP are in qualitative agreement, but there are non-negligible offsets and differences between them, especially near the westward velocity peak and drift reversal.

\section{Discussion}

In this study we have presented the distribution of zonal plasma drift at low latitudes, estimated indirectly from CHAMP observations. The method was suggested earlier by Park and Lühr (2012), but applied then only to a limited period around the major sudden stratospheric warming (SSW) event in December 2001. For a qualitative verification, Park and Lühr (2012) compared their results (averaged over all the GLON sectors) with the climatological drift model of Fejer et al. (2005) (obtained at Jicamarca).

In the current study we make use of CHAMP and ROCSAT-1 measurements during 3 years of high solar activity. This larger data set results in a finer resolution in GLON, LT, and season. CHAMP estimates have been directly compared with ROCSAT-1 plasma drift observations for validation purposes. Since the orbits of the two satellites are very different in terms of altitudes and inclination angles, a statistical approach is used: the two $v_{\mathrm{y}}$ values are compared in bins of GLON, LT, and season. A favourable correlation coefficient, $R \geq 0.84$ during December solstice and equinox, confirms the general agreement of plasma drift velocities from the two satellites. Also, the ratio between the two drift velocities is close to unity. We may conclude that the $v_{\mathrm{y}}$ estimated from CHAMP data has a reasonable reliability.

Concerning certain differences between ROCSAT-1 and CHAMP plasma drifts, we compare both results with previous works. Fejer et al. (2005) conducted a climatological study on zonal plasma drift above Jicamarca near the F region peak (typically $300-500 \mathrm{~km}$ ), which is similar to the CHAMP orbit altitude. For high solar activity periods, daytime westward drift in general maximizes at 11:30-12:00 LT, 12:30-13:00 LT, and 11:00-11:30 LT during equinox, June solstice, and December solstice, respectively (Fejer et al., 2005, Fig. 1). In our Fig. 3 westward drifts estimated by CHAMP around $280^{\circ} \mathrm{E}$ GLON generally peak at 09:0011:00 LT during the three respective seasons. In the same GLON sector, our Fig. 5 shows westward drift maxima for ROCSAT-1 generally at 12:00-13:00 LT during the three respective seasons. Concerning the LT of maximum westward drift, the results of Fejer et al. (2005) show better agreement with ROCSAT-1 data (our Fig. 5) than with CHAMP estimates (our Fig. 3).

In Fig. 1 of Fejer et al. (2005) zonal plasma drift for high solar activity periods reverses from westward to eastward between 16:00 LT and 17:00 LT in all seasons. In our Fig. 3 (CHAMP) zonal plasma drift around 

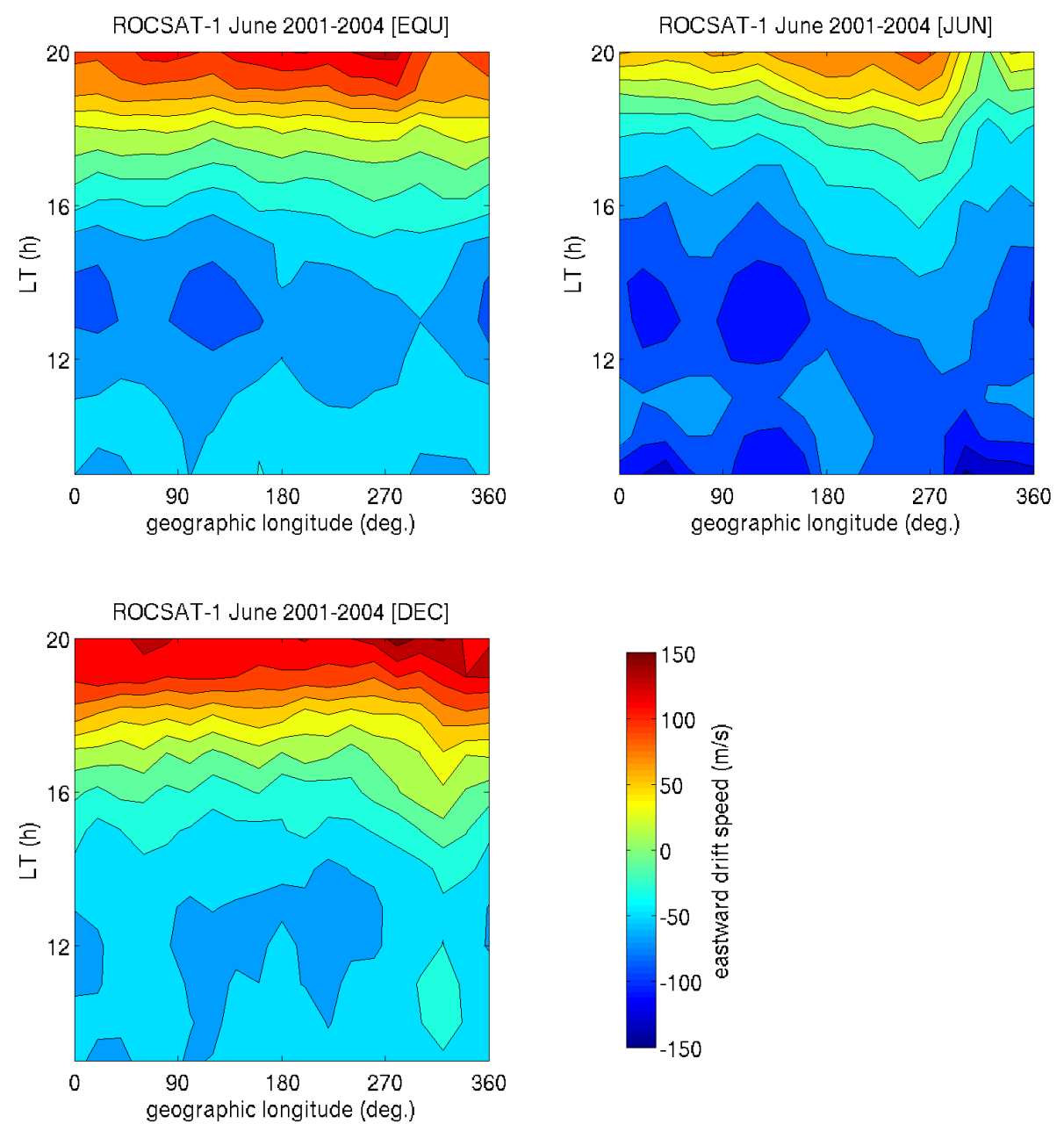

Fig. 5. Same as Fig. 2, but for average zonal plasma drift velocity observed by the ROCSAT-1/IPEI.

$280^{\circ} \mathrm{E}$ GLON generally reverses from westward to eastward at 15:00-16:00 LT. Compared to Fejer et al. (2005) the reversals in CHAMP data appear about an hour early. In the case of ROCSAT-1 (see our Fig. 5) the reversal times at $280^{\circ}$ E GLON are 16:00-17:00 LT, 17:00-18:00 LT, and 15:00-16:00 LT during the respective seasons. According to Su et al. (2009) mean reversal times in the Jicamarca sector are 16:40 LT and 15:20 LT for June and December solstice months, respectively, which is consistent with our Fig. 5. Concerning the LT of $v_{\mathrm{y}}$ reversal, ROCSAT- 1 measurements are in better agreement with Fejer et al. (2005) than CHAMP estimates are.

According to the San Marco D observations at 350$700 \mathrm{~km}$ apex altitudes (Maynard et al., 1995, Fig. 4), $v_{\mathrm{y}}$ changes sign near 16:00 LT in equinox and solstice. Note that these observations are not limited to the Jicamarca location. In our Figs. 3 and 4, the reversal times of CHAMP $v_{\mathrm{y}}$ are slightly before 16:00 LT on average. In our Fig. 5 and Fig. 4 of Su et al. (2009) the reversal times of ROCSAT$1 v_{\mathrm{y}}$ are near 17:00 LT on average. Hence, the $v_{\mathrm{y}}$ reversal time of San Marco-D data (16:00 LT) is consistent with the CHAMP estimates rather than with the ROCSAT-1 observations. $v_{\mathrm{y}}$ reversal time in Fig. 3 (CHAMP) depends little on seasons. Conversely, ROCSAT-1 measurements in our Fig. 5 and in Su et al. (2009, Fig. 4) show that the $v_{\mathrm{y}}$ reversal time is much later during June solstice than in the other seasons. As a consequence, the intercept of the regression line in Fig. 6 is largest during June solstice (about $40 \mathrm{~m} \mathrm{~s}^{-1}$ ), which corresponds to the delayed reversal of ROCSAT- 1 v with respect to CHAMP $v_{\mathrm{y}}$. We note that the reversal time in Maynard et al. (1995, Fig. 4) and Fejer et al. (2005, Fig. 2) exhibits no conspicuous delay during June solstice, which agrees with our Fig. 3 (CHAMP) rather than with our Fig. 5 (ROCSAT1). Daytime westward drift shown in Maynard et al. (1995, Fig. 4) maximizes at 13:00 LT for both equinox and solstice. It is in better agreement with ROCSAT-1 observations (our Fig. 5) than with CHAMP estimates (our Fig. 3).

As discussed in the preceding paragraphs, $v_{\mathrm{y}}$ measured by ROCSAT- 1 and that estimated by CHAMP exhibit some discrepancies in the local times of $v_{\mathrm{y}}$ reversal and of maximum 

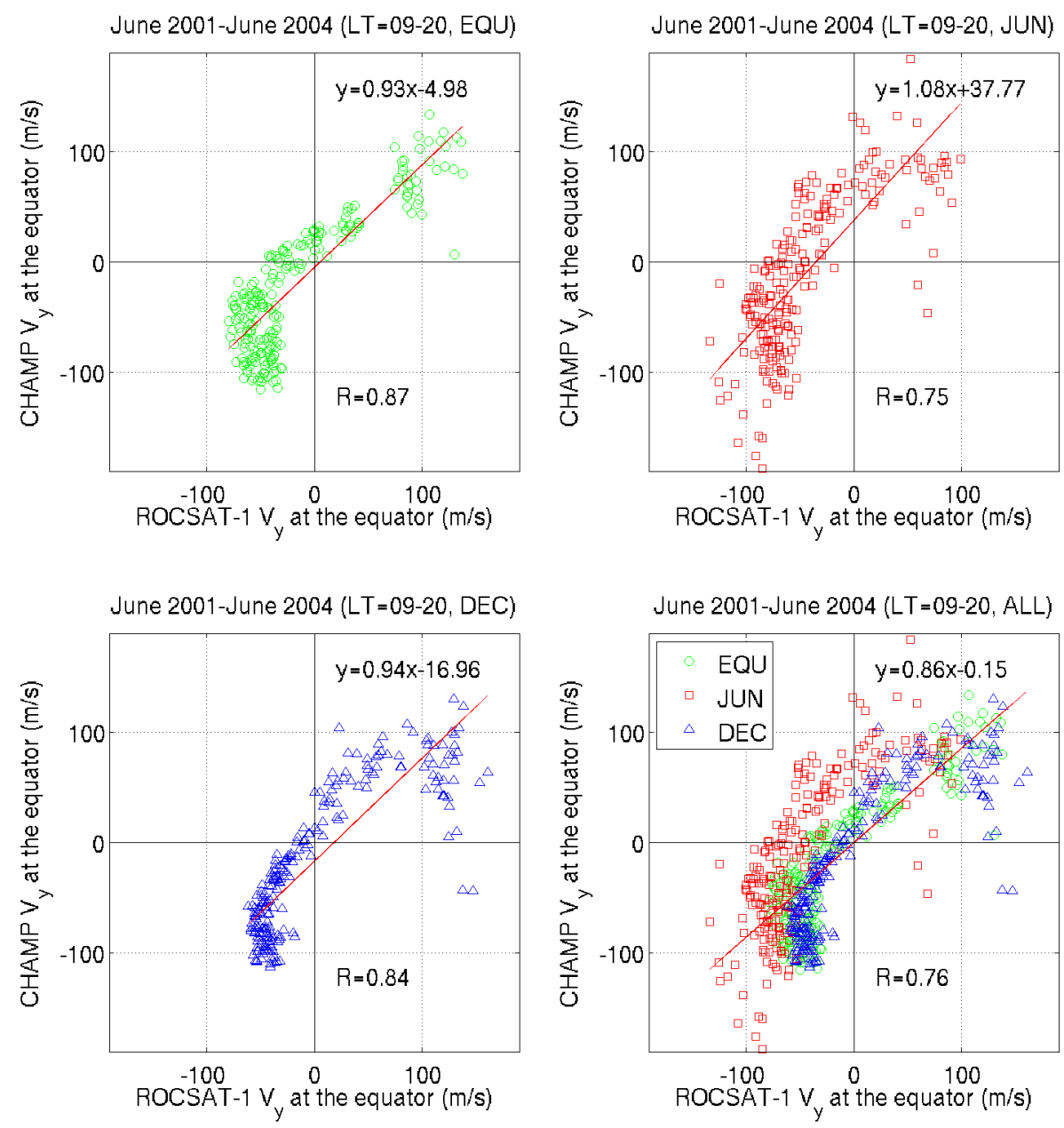

Fig. 6. The correlation diagram between Figs. 3 and 5 for each season. The bottom-right panel contains all the data points in the other panels.

westward drift. Concerning these differences, previous studies generally support the ROCSAT- 1 observations, but not always (e.g. Maynard et al., 1995, Fig. 4). Hence, there seem to be multiple factors that compromise the agreement of $v_{\mathrm{y}}$ between CHAMP and ROCSAT-1. First, assumptions used for $v_{\mathrm{y}}$ estimation from CHAMP data can contribute to the discrepancies. Especially, the empirical equation of ionneutral collision frequency $\left(v_{\text {in }}=3.67 \times 10^{-17} n_{\mathrm{n}} \sqrt{T_{r}}(1-\right.$ $\left.0.064 \log _{10} T_{\mathrm{r}}\right)^{2}$ ) may need additional correction terms depending on LT, GLON, and season. Second, CHAMP observations may also have some uncertainties, e.g. zonal wind uncertainty of about $20 \mathrm{~m} \mathrm{~s}^{-1}$ as mentioned by Liu et al. (2006). Also, $v_{\mathrm{y}}$ measured by ROCSAT- 1 may have non-negligible uncertainties as the velocity component is deduced primarily from the along-track drift measurements. For this component an uncertainty of $\pm 37.8 \sim 75.45 \mathrm{~m} \mathrm{~s}^{-1}$ is quoted in http://cdaweb.gsfc.nasa.gov/misc/NotesR.html.

We discuss the relative contributions from the ionospheric $\mathrm{E}$ and $\mathrm{F}$ regions to the vertical currents in the equatorial $\mathrm{F}$ region. The daytime $v_{\mathrm{y}}$ at $\mathrm{F}$ region altitudes is driven primarily by the meridional electric field generated in the $\mathrm{E}$ layer (e.g. Heelis, 2004, Eq. 11). This electric field maps up from low latitudes to CHAMP and ROCSAT- 1 altitudes and causes the zonal plasma flow. The zonal wind in the $\mathrm{F}$ region blows in the same direction as the plasma drift (westward during daytime and eastward in the evening and at night), thus experiencing a much reduced ion drag. In our Figs. 2-3 the neutral wind is generally faster (in magnitude) than the ion drift, which agrees with Coley et al. (1994, Fig. 2). In our Fig. 4 we show the large and oppositely directed contribution of the zonal neutral wind and $v_{\mathrm{y}}$ (vertical polarization $\mathrm{E}$ field) to $F$ region vertical currents, which has not been appreciated appropriately in some of the earlier studies (e.g. Lühr and Maus, 2006; Park et al., 2010). Our observations demonstrate not only that the $\mathrm{E}$ region is a high-conductivity load for the $\mathrm{F}$ region wind dynamo currents, but also that the $\mathrm{E}$ field generated by $\mathrm{E}$ region zonal wind affects the net $\mathrm{F}$ region vertical current significantly via the polarization electric field.

We have shown that zonal plasma drift in the equatorial $\mathrm{F}$ region can be estimated reasonably well without any ion drift meter, if electron/neutral/magnetic observations in 
the $\mathrm{F}$ region are available. The reliability of the estimation will be improved when we have further information on ion temperature and composition (see Eq. 3), which were unavailable for this study. The upcoming constellation mission of the European Space Agency, "Swarm", consists of three identical CHAMP-like satellites. The Swarm satellites can measure all the ionospheric parameters obtained by CHAMP as well as ion temperature, composition, and drift velocity. The ion temperature and composition can give further constraints to Eq. (3), and the estimated $v_{\mathrm{y}}$ can be compared directly to $v_{\mathrm{y}}$ measured by Swarm. Moreover, one of the Swarm satellites will be at higher altitudes than the others. This formation may help to clarify whether some of the discrepancies between the CHAMP estimation and the ROCSAT-1 observation (see Fig. 6) reflect a real altitude dependence of $v_{\mathrm{y}}$. With the advent of the next solar maximum, when the F region vertical currents are expected to be strong and clearly measurable, the Swarm satellites should provide an opportunity to validate our method of $v_{\mathrm{y}}$ estimation more thoroughly and extensively.

\section{Summary}

Following the method suggested by Park and Lühr (2012), we have estimated zonal plasma drift velocity in the 09:0020:00 LT sector using electron/neutral/magnetic observations of CHAMP. For the period from June 2001 to June 2004 the estimated values are validated against ion drift measurements by ROCSAT-1/IPEI, and are compared with results from previous ionospheric studies. Our main conclusions can be summarized as follows:

1. The plasma drifts estimated from CHAMP data are in reasonable agreement with the measurements by ROCSAT-1. A direct comparison of the data reveals a high linear correlation $(R \approx 0.8)$ for data obtained between 09:00 and 20:00 LT. The slope of the regression line is close to unity for all seasons (Fig. 6).

2. $v_{\mathrm{y}}$ estimated from CHAMP data show some discrepancies with the ROCSAT- 1 measurements. $v_{\mathrm{y}}$ measured by ROCSAT-1 (estimated from CHAMP data) generally exhibits peak westward velocities after (before) noon. The reversal from westward to eastward zonal plasma drift, as estimated from CHAMP data, is earlier by about $1-2 \mathrm{~h}$ than ROCSAT- 1 observations. Concerning these differences, some previous studies support the ROCSAT-1 observations, while others agree better with the CHAMP estimates.

3. During most parts of daytime, zonal wind and plasma drift generally point in the same direction in the equatorial $\mathrm{F}$ region. This significantly reduces the ion drag effect on the neutrals. The reduced ion drag is one of the main causes of the high wind speeds along the magnetic equator, as reported by Liu et al. (2009).
4. Zonal wind and plasma drift (or, equivalently, vertical polarization $\mathrm{E}$ field) contribute to the vertical $\mathrm{F}$ region current in opposite directions: e.g. an eastward wind drives upward currents, while an eastward plasma drift (or, equivalently, downward polarization E-field) causes downward current. In general the former effect $(\boldsymbol{u} \times \boldsymbol{B}$ wind dynamo) is lager in magnitude than the latter (Pedersen current), determining the direction of the net vertical current in the equatorial $\mathrm{F}$ region.

Acknowledgements. The CHAMP mission was sponsored by the Space Agency of the German Aerospace Center (DLR) through funds of the Federal Ministry of Economics and Technology, following a decision of the German Federal Parliament (grant code 50EE0944). The CDAWeb data were obtained from the interface at http://cdaweb.gsfc.nasa.gov/. We are also grateful to the NCU ROCSAT-1/IPEI team members for their efforts in processing the ROCSAT-1/IPEI data.

The service charges for this open access publication have been covered by a Research Centre of the Helmholtz Association.

Topical Editor K. Hosokawa thanks two anonymous referees for their help in evaluating this paper.

\section{References}

Basu, S., MacKenzie, E., and Basu, S.: Ionospheric constraints on VHF/UHF communications links during solar maximum and minimum periods, Radio Sci., 23, 363-378, doi:10.1029/RS023i003p00363, 1988.

Basu, S., Basu, S., Groves, K. M., Yeh, H.-C., Su, S.-Y., Rich, F. J., Sultan, P. J., and Keskinen, M. J.: Response of the equatorial ionosphere in the South Atlantic Region to the Great Magnetic Storm of July 15, 2000, Geophys. Res. Lett., 28, 3577-3580, doi:10.1029/2001GL013259, 2001.

Chen, G., Zhao, Z., Ning, B., Deng, Z., Yang, G., Zhou, C., Yao, M., Li, S., and Li, N.: Latitudinal dependence of the ionospheric response to solar eclipse of 15 January 2010, Geophys. Res. Lett., 116, A06301, doi:10.1029/2010JA016305, 2011.

Coley, W. R., Heelis, R. A., and Spencer, N. W.: Comparison of lowlatitude ion and neutral zonal drifts using DE 2 data, J. Geophys. Res., 99, 341-348, doi:10.1029/93JA02205, 1994.

de Paula, E. R., Kantor, I. J., Sobral, J. H. A., Takahashi, H., Santana, D. C., Gobbi, D., de Medeiros, A. F., Limiro, L. A. T., Kil, H., Kintner, P. M., and Taylor, M. J.: Ionospheric irregularity zonal velocities over Cachoeira Paulista, J. Atmos. Solar Terr. Phys., 64, 1511-1516, ISSN 1364-6826, 10.1016/S13646826(02)00088-3, 2002.

England, S. L. and Immel, T. J.: An empirical model of the drift velocity of equatorial plasma depletions, J. Geophys. Res., 117, A12308, doi:10.1029/2012JA018091, 2012.

Fejer, B. G., Souza, J. R., Santos, A. S., and Costa Pereira, A. E.: Climatology of F region zonal plasma drifts over Jicamarca, J. Geophys. Res., 110, A12310, doi:10.1029/2005JA011324, 2005.

Fejer, B. G., Jensen, J. W., and Su, S.-Y.: Quiet time equatorial $\mathrm{F}$ region vertical plasma drift model derived from 
ROCSAT-1 observations, J. Geophys. Res., 113, A05304, doi:10.1029/2007JA012801, 2008.

Hartman, W. A. and Heelis, R. A.: Longitudinal variations in the equatorial vertical drift in the topside ionosphere, J. Geophys. Res., 112, A03305, doi:10.1029/2006JA011773, 2007.

Heelis, R. A.: Electrodynamics in the low and middle latitude ionosphere: a tutorial, J. Atmos. Solar Terr. Phys., 66, 825-838, doi:10.1016/j.jastp.2004.01.034, 2004.

Jee, G., Schunk, R. W., and Scherliess, L.: Analysis of TEC data from the TOPEX/Poseidon mission, J. Geophys. Res., 109, A01301, doi:10.1029/2003JA010058, 2004.

Kil, H., Kintner, P. M., de Paula, E. R., and Kantor, I. J.: Latitudinal variations of scintillation activity and zonal plasma drifts in South America, Radio Sci., 37, 1006, doi:10.1029/2001RS002468, 2002.

Kil, H., Oh, S.-J., Kelley, M. C., Paxton, L. J., England, S. L., Talaat, E., Min, K.-W., and Su, S.-Y.: Longitudinal structure of the vertical E $\times$ B drift and ion density seen from ROCSAT-1, Geophys. Res. Lett., 34, L14110, doi:10.1029/2007GL030018, 2007.

Liu, H., Lühr, H., Watanabe, S., Köhler, W., Henize, V., and Visser, P.: Zonal winds in the equatorial upper thermosphere: Decomposing the solar flux, geomagnetic activity, and seasonal dependencies, J. Geophys. Res., 111, A07307, doi:10.1029/2005JA011415, 2006.

Liu, H., Watanabe, S., and Kondo, T.: Fast thermospheric wind jet at the Earth's dip equator, Geophys. Res. Lett., 36, L08103, doi:10.1029/2009GL037377, 2009.

Lühr, H. and Maus, S.: Direct observation of the F region dynamo currents and the spatial structure of the EEJ by CHAMP, Geophys. Res. Lett., 33, L24102, doi:10.1029/2006GL028374, 2006.

Manju, G., Sreeja, V., Ravindran, S., and Thampi, S. V.: Toward prediction of $\mathrm{L}$ band scintillations in the equatorial ionization anomaly region, J. Geophys. Res., 116, A02307, doi:10.1029/2010JA015893, 2011.

Martinis, C., Eccles, J. V., Baumgardner, J., Manzano, J., and Mendillo, M.: Latitude dependence of zonal plasma drifts obtained from dual-site airglow observations, J. Geophys. Res., 108, 1129, doi:10.1029/2002JA009462, 2003.

Maynard, N. C., Aggson, T. L., Herrero, F. A., Liebrecht, M. C., and Saba, J. L.: Average equatorial zonal and vertical ion drifts determined from San Marco D electric field measurements, J. Geophys. Res., 100, 17465-17479, doi:10.1029/95JA00767, 1995.
Nishioka, M., Basu, Su., Basu, S., Valladares, C. E., Sheehan, R. E., Roddy, P. A., and Groves, K. M.: C/NOFS satellite observations of equatorial ionospheric plasma structures supported by multiple ground-based diagnostics in October 2008, J. Geophys. Res. 116, A10323, doi:10.1029/2011JA016446, 2011.

Noja, M., Stolle, C., Park, J., and Lühr, H.: Long term analysis of ionospheric polar patches based on CHAMP TEC data, Radio Sci., in press, doi:10.1002/rds.20033, 2013.

Pacheco, E. E., Heelis, R. A., and Su, S.-Y.: Superrotation of the ionosphere and quiet time zonal ion drifts at low and middle latitudes observed by Republic of China Satellite-1 (ROCSAT-1), J. Geophys. Res., 116, A11329, doi:10.1029/2011JA016786, 2011.

Park, J. and Lühr, H.: Effects of sudden stratospheric warming (SSW) on the lunitidal modulation of the $\mathrm{F}$ region dynamo, J. Geophys. Res., 117, A09320, doi:10.1029/2012JA018035, 2012.

Park, J., Lühr, H., and Min, K. W.: Characteristics of $\mathrm{F}$ region dynamo currents deduced from CHAMP magnetic field measurements, J. Geophys. Res., 115, A10302, doi:10.1029/2010JA015604, 2010.

Sastri, J. H.: Longitudinal dependence of equatorial F region vertical plasma drifts in the dusk sector, J. Geophys. Res., 101, 24452452, doi:10.1029/95JA02759, 1996.

Scherliess, L. and Fejer, B. G.: Radar and satellite global equatorial F region vertical drift model, J. Geophys. Res., 104, 6829-6842, doi:10.1029/1999JA900025, 1999.

Schunk, R. W. and Nagy, A. F.: Ionospheres: Physics, Plasma Physics, and Chemistry, Second Edition, Cambridge Univ. Press, 2009.

Stolle, C., Manoj, C., Lühr, H., Maus, S., and Alken, P.: Estimating the daytime Equatorial Ionization Anomaly strength from electric field proxies, J. Geophys. Res., 113, A09310, doi:10.1029/2007JA012781, 2008.

Su, S.-Y., Yeh, H. C., and Heelis, R. A.: ROCSAT 1 ionospheric plasma and electrodynamics instrument observations of equatorial spread F: An early transitional scale result, J. Geophys. Res., 106, 29153-29159, doi:10.1029/2001JA900109, 2001.

Su, S.-Y., Chao, C. K., and Liu, C. H.: Cause of different local time distribution in the postsunset equatorial ionospheric irregularity occurrences between June and December solstices, J. Geophys. Res., 114, A04321, doi:10.1029/2008JA013858, 2009. 